\title{
Transcription factors and molecular epigenetic marks underlying EpCAM overexpression in ovarian cancer
}

\author{
BTF van der Gun', ML de Groote', HG Kazemier', AJ Arendzen', P Terpstra ${ }^{2}$, MHJ Ruiters',3, PMJ McLaughlin' \\ and MG Rots*,I \\ 'Epigenetic Editing, Department of Pathology and Medical Biology, University Medical Centre Groningen, University of Groningen, Hanzeplein I, \\ 97 I 3 GZ Groningen, The Netherlands; '2Epidemiology, Department of Genetic Epidemiology and Bioinformatics, University Medical Centre Groningen, \\ University of Groningen, Hanzeplein I, 9713 GZ Groningen, The Netherlands; ${ }^{3}$ Synvolux Therapeutics Inc., LI. Zielstraweg I, 97 I 3 GX Groningen, \\ The Netherlands
}

BACKGROUND: The epithelial cell adhesion molecule (EpCAM) is overexpressed on carcinomas, and its downregulation inhibits the oncogenic potential of multiple tumour types. Here, we investigated underlying mechanisms of epcam overexpression in ovarian carcinoma.

METHODS: Expression of EPCAM and DNA methylation (bisulphite sequencing) was determined for ovarian cancer cell lines. The association of histone modifications and 16 transcription factors with the epcam promoter was analysed by chromatin immunoprecipitation. Treatment with 5-Aza-2'-deoxycytidine (5-AZAC) was used to induce EpCAM expression.

RESULTS: Expression of EPCAM was correlated with DNA methylation and histone modifications. Treatment with 5-AZAC induced EpCAM expression in negative cells. Ten transcription factors were associated with the epcam gene in EpCAM expressing cells, but not in EpCAM-negative cells. Methylation of an Spl probe inhibited the binding of nuclear extract proteins in electromobility shift assays; such DNA methylation sensitivity was not observed for an NF- $\kappa$ B probe.

CONCLUSION: This study provides insights in transcriptional regulation of epcam in ovarian cancer. Epigenetic parameters associated with EpCAM overexpression are potentially reversible, allowing novel strategies for sustained silencing of EpCAM expression.

British Journal of Cancer (2011) I 05, 312-319. doi:10.1038/bjc.2011.231 www.bjcancer.com

Published online 21 June 20II

(c) 201। Cancer Research UK

Keywords: ovarian cancer; EpCAM; DNA methylation; histone modifications; transcription factors

The epithelial cell adhesion molecule (EpCAM; CD326) is a transmembrane glycoprotein, highly overexpressed on most carcinomas. Recently, EpCAM also gained interest as a signal transducer (Maetzel et $a l, 2009$ ) and as a marker of cancerinitiating cells (Visvader and Lindeman, 2008). The role of EpCAM in the development of cancer and in tumour progression is dependent on the tumour type as recently reviewed by us (van der Gun et al, 2010b). For example, in breast cancer, high EpCAM expression correlates with poor prognosis (Spizzo et al, 2004), and downregulation of EpCAM has been shown to decrease the oncogenic potential (Osta et al, 2004). In contrast, high EpCAM expression in, for example, primary renal cell carcinomas is associated with improved patient survival (Seligson et al, 2004; Klatte et al, 2009). In other types of carcinoma such as ovarian cancer, the role of EpCAM is not clear and contradictory results have been reported.

In normal ovary and benign ovarian tumours, EpCAM expression is lower compared with malignant ovarian tumours (Kim et al, 2003). Numerous studies confirmed the EpCAM overexpression in ovarian carcinomas (Heinzelmann-Schwarz et al, 2004; Spizzo et al, 2006; Kobel et al, 2008), turning EpCAM

*Correspondence: Professor MG Rots; E-mail: M.G.Rots@med.umcg.nl Received 28 January 20 I ; revised 19 May 201 I; accepted 24 May 201 I; published online 21 June 20 I I into a well-established ovarian tumour marker (Spizzo et al, 2011). The role of EpCAM in ovarian tumour progression, however, is unclear; one study reported that FIGO stage III/IV showed lower EpCAM expression than stage I (Kim et al, 2003), while in another study, FIGO stage III/IV showed higher EpCAM expression than stage I/II disease (Heinzelmann-Schwarz et al, 2004). Importantly, metastatic and recurrent tumours were found to express significantly higher levels of EpCAM protein when compared with primary ovarian carcinomas (Bellone et al, 2009). Despite some contradictory results, the observations suggest a promoting rather than a protecting role for EpCAM in ovarian cancer. This promoting role is further confirmed for patients with stage III/IV disease, for whom EpCAM overexpression was shown to correlate significantly with decreased overall survival (Spizzo et al, 2006).

Besides its possible prognostic role in ovarian cancer, EpCAM is used as a therapeutic immunotarget for the treatment of malignant ascites. For example, catumaxomab is a trifunctional monoclonal antibody (anti-EpCAM $\times$ anti-CD3) approved to treat ovarian cancer patients with malignant ascites (Bokemeyer, 2010). Recently, it has been reported that catumaxomab treatment might also have an effect on tumour cells in blood of ovarian cancer patients (Wimberger et al, 2009). Similarly, the human monoclonal antibody MT201 could effectively eliminate malignant cells in metastic tumour specimens from patients with ovarian cancer (Xiang et al, 2003). 
For various tumour types, EpCAM overexpression has been associated with DNA hypomethylation of the promoter and treatment of EpCAM-negative cells with a DNA methylation inhibitor induced EpCAM expression (Spizzo et al, 2007; Tai et al, 2007; van der Gun et al, 2008). Alternatively, we also demonstrated that endogenous EpCAM expression can be actively downregulated by nuclear delivery of a DNA methyltransferase (van der Gun et al, 2008). Here, we investigate epigenetic mechanisms and transcription factors underlying the overexpression of EpCAM in ovarian cancer. Unlike genetic mutations, epigenetic mutations are reversible; a better understanding of the regulation of EpCAM gene expression may thus provide new opportunities for cancer therapy, based on reversing epigenetic marks.

\section{MATERIALS AND METHODS}

\section{Cell culture and 5-AZAC treatment}

Ovarian cancer cell lines (H134S, SKOV3, CaOV3, OVCAR3) were cultured in DMEM (BioWhittaker, Walkersville, MD, USA) and A2780 in RPMI-1640 (BioWhittaker) with $50 \mu \mathrm{g} \mathrm{ml}^{-1}$ gentamicin sulphate, $2 \mathrm{~mm}$ L-glutamine and $10 \%$ FBS. Culture medium of A2780 contained also $1 \mathrm{~mm}$ Na-pyruvaat and $0.05 \mathrm{~mm} \beta$-mercaptoethanol. For DNA methylation inhibition studies, H134S and A2780 were cultured in their appropriate media with a final concentration of $5 \mu \mathrm{m}$ 5-Aza-2'-deoxycytidine (5-AZAC; Sigma, St Louis, MO, USA). Everyday, freshly prepared 5-AZAC was added, and after 3 days, cells were harvested for extraction of protein and mRNA.

\section{EpCAM protein expression}

EpCAM protein was detected by mouse Mab MOC31 hybridoma supernatant, followed by $\mathrm{R} \alpha \mathrm{M}-\mathrm{F}(\mathrm{ab})_{2}$-FITC (DAKO, Glostrup, Denmark) or mouse CD326-APC (Biolegend, Uithoorn, the Netherlands). The mean fluorescence intensity (MFI) was measured on a Calibur flow cytometer (Beckton Dickinson Biosciences, San Jose, CA, USA).

\section{Quantitative gene expression analysis by real-time RT-PCR}

RNA was isolated using Rneasy Mini Kit (Qiagen, Venlo, The Netherlands); $1 \mu \mathrm{g}$ was reverse-transcribed (RevertAid cDNA Synthesis Kit (Fermentas, Leon-Rot, Germany). The Q-PCR analysis was performed (ABIPrism 7900HT, Applied Biosystems, Nieuwekerk, the Netherlands) for EpCAM (Hs00158980_m1, Applied Biosystems) and GAPDH (F5'-CCACATCGCTCAGACAC CAT-3', R5'-GCGCCCAATACGACCAAAT-3', probe: CGTTGACTC CGACCTTCACCTTCCC (Eurogentec, Maastricht, the Netherlands)) in triplicate. Relative gene expression levels were calculated based on the comparative cycle treshold $\left(C_{\mathrm{t}}\right)$ method $\left(\Delta C_{\mathrm{t}}=C_{\mathrm{t}}\right.$ EpCAM $-C_{\mathrm{t}}$ GAPDH). To compare EpCAM expression of different samples, the differences in $\Delta C_{\mathrm{t}}$ of individual samples $\left(\Delta \Delta C_{\mathrm{t}}\right)$ were used (A2780 was set at 1).

\section{DNA methylation analysis}

EZ DNA Methylation-Gold Kit (Baseclear Lab Products, Leiden, the Netherlands) was used to modify $1 \mu \mathrm{g}$ of DNA. DNA methylation analysis was performed as described (van der Gun et al, 2010a). Bisulphite primer sequences for regions $\mathrm{A}$ and $\mathrm{B}$ are depicted in Figure 1A. The correlation between EpCAM expression and DNA methylation was assessed by Spearman's correlation test.

\section{Chromatin immunoprecipitation}

Histone marks were determined according to the Upstate Biotechnology (Lake Placid, NY, USA) protocol and association of transcription factors was detected as described (Weinmann and Farnham, 2002) (see Supplementary Materials and Methods). Real-time PCR was performed using AbsoluteQPCR SYBRGreenROXMix (Abgene, Surrey, UK), ABI7900HT. The \% input was expressed as $\mathrm{AE}^{\left(C_{t} \text { input }-C_{\mathrm{t}} \mathrm{ChIP}\right)} \times \mathrm{Fd} \times 100 \%$, where $\mathrm{Fd}$ is a dilution compensatory factor and $\mathrm{AE}$ represents the primer efficiency. Primers for regions A1, B1, B2 and C are depicted in Figure 1A and underlined in Figure $1 \mathrm{~B}$.

\section{Electromobility shift assay}

OVCAR3 nuclear extract was prepared using an NE-PER kit (Pierce Biotechnology, Etten-Leur, the Netherlands). RDY681labelled probes (Isogen, De Meern, the Netherlands) are depicted in Figure 1B. Probes were incubated with $4 \mu \mathrm{g}$ nuclear extract in $20 \mu \mathrm{l}$ binding buffer (Pierce Biotechnology) for $20^{\prime}$ at RT. For competition assays, a 100-fold excess of unlabelled competitor was premixed with RDY681-labelled probe and added to the binding mixture. Probes were in vitro methylated by M.SssI (New England Biolabs, Ipswich, MA, USA). Unmethylated probes were treated similarly but in the absence of methyl donor. Non-denaturing $4 \%$ polyacrylamide gels were visualised using Odyssey Scanner (Westburg, Leusden, the Netherlands).

\section{RESULTS}

EpCAM expression in correlation with DNA methylation in ovarian cancer

Ovarian cancer cell lines were selected based on their EpCAM protein expression levels: two EpCAM-negative lines (H134S, A2780; MFI: $4.6 \pm 0.05,2.6 \pm 0.14$, respectively), SKOV3 with an intermediate EpCAM expression level (MFI: $104 \pm 3$ ) and two cell lines (CaOV3, OVCAR3) with a high EpCAM expression level (MFI: $461 \pm 30 ; 496 \pm 24$, respectively) (Figure $2 \mathrm{~A}$ ). The protein data are in line with the EpCAM mRNA levels (Figure 2B). To determine the role of DNA methylation in silencing EpCAM expression, the EpCAM-negative cell lines were treated with a DNA methylation inhibitor. Indeed, treatment with 5-AZAC resulted in induction of EpCAM expression in the EpCAM-negative cell lines $\mathrm{H} 134 \mathrm{~S}$ and A2780, both on protein and mRNA level (Figures 2A and $\mathrm{B})$. To further investigate the correlation between EpCAM expression and DNA methylation, the methylation status of the epcam promoter and part of exon 1 was analysed. In the EpCAMnegative cell lines, the $61 \mathrm{CpGs}$ present in region $\mathrm{A}$ were hypermethylated (A2780: $100 \pm 0 \%$; H134S: $89 \pm 23 \%$ ), whereas region $\mathrm{A}$ in EpCAM-positive cell lines was hypomethylated (SKOV3: $1 \pm 3 \%$; CaOV3: $0.5 \pm 3 \%$; OVCAR3: $0 \pm 2 \%$ ) (Figure $2 \mathrm{C}$, Table 1). Interestingly, low to undetectable EpCAM-expressing normal epithelial ovarian cancer cells (HOSE) (Kim et al, 2003; Bellone et al, 2009) displayed a variable DNA methylation level of $15 \pm 21 \% \quad(n=10$ clones $)$. For region $\mathrm{B}$ (18 CpGs), the DNA methylation levels were $99 \pm 2,56 \pm 17,9 \pm 13,3 \pm 6,1 \pm 5 \%$ for A2780, H134S, SKOV3, CaOV3, OVCAR3, respectively, (Figure 2C, Table 1). In the cell lines, an inverse correlation between EpCAM expression and DNA methylation was found (Spearman $r=-0.97$, $P=0.02$, Region A).

\section{Histone modifications associated with EpCAM expression}

In EpCAM-positive cells, regions C and B2 were associated with acetylated histone $4(\mathrm{acH} 4)$, acetylated histone $3(\mathrm{acH} 3)$ and with trimethylation of lysine 4 of histone 3 (H3K4me3) (Figures $3 \mathrm{~A}$ and $\mathrm{B}$, Table 1). For region A1 covering the TSS, the presence of these active marks was even more pronounced (Figure $3 \mathrm{C}$ ). In EpCAM-negative cells, association of these histone modifications was not detected, except for low levels of acH3 up to $1 \%$ of input DNA at region A1 (Figure 3D). 
A

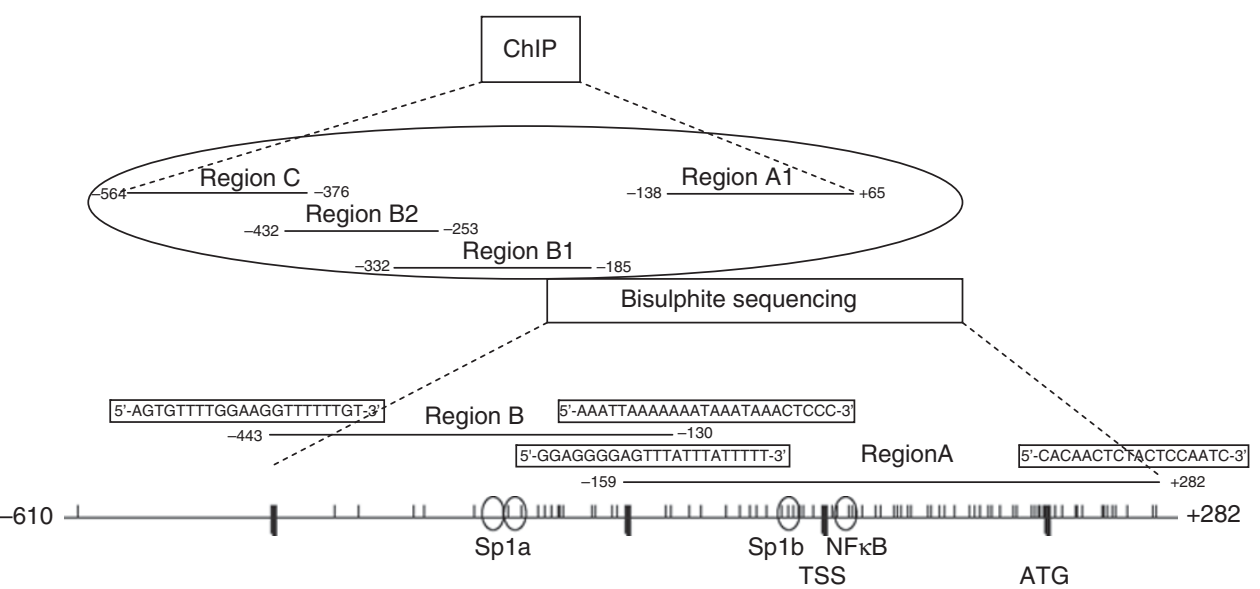

B

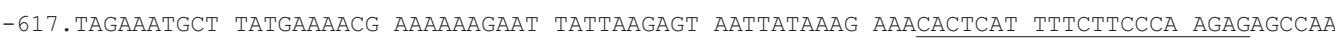
PU1.01/Ets LEF1 LEF1

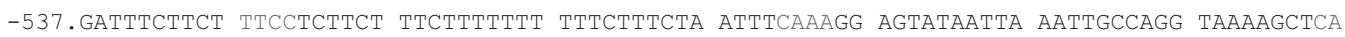
Start region $B$ B2 PU1.01/EtS C STAT1

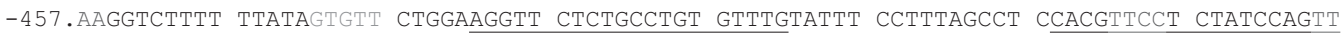
$\mathrm{E} 2 \mathrm{~F} 4$ $\mathrm{AP}-2$ B1 PEA3 -377. CCCGCACCCT TCCCCCCAGG CCCCATTCTT CAAGGCTTCA GAGCAGCGCT CCTCCGGTTA AAAGGAAgtC TCAGCACAgA LEF1 B2 SP1/Sp1a -297. ATCTTCAAAC CTCCTCGGAG GCCACCAAAG ATCCCTAACG CCGCCATGGA GACGAAGCAC CTGGGGCGGG GCGGAGCGGG B1 RNApoIIIB Spl Start region A -217. GCGCGCGGGC CCACACCTGT GGAGAGGGCC GCGCCCCAAC TGCAGCGCCG GGGCTGGGGG AGGGGAGCCT ACTCACTCCC A1 SP1 AP-1 STAT1/3/EtS

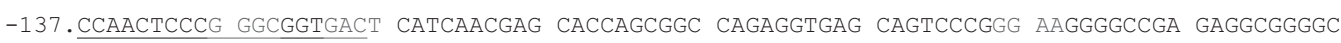

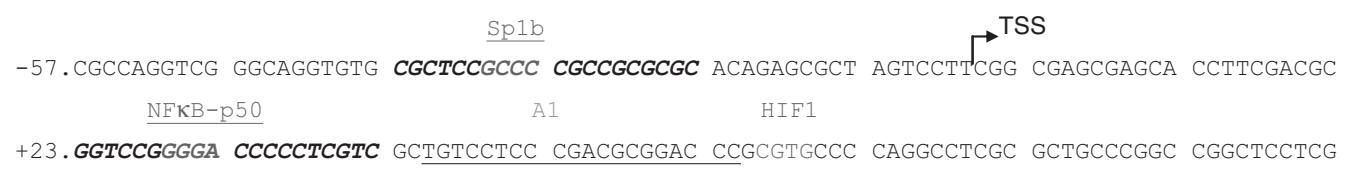
+103. TGTCCCACTC CCGGCGCACG CCCTCCCGCG AGTCCCGGG CCCTCCCGCG CCCCTCTTCT CGGCGCGCGC GCAGCATGGC +183. GCCCCCGCAg GTCCTCGCGT TCGGGCTTCT GCTTGCCGCG GCGACGGCGA CTTTTGCCGC AGCTCAgGAA GGTGAgGCGC

Figure I Part of the epcam gene under investigation. (A) Schematic overview: nucleotide position -610 to +282 relative to the transcription starting site (TSS); the ATG start codon is shown; CpGs are depicted by vertical bars. Regions A and B were analysed for DNA methylation, region C, B2 and A I for histone modifications, and region BI and A I for transcription factors. Open circles represent putative SpI and NF- $\kappa$ B binding sites. (B) Nucleotide positions -617 to +282 relative to the TSS are shown; the ATG start codon is depicted in bold. The start site of regions A and B is indicated in blue and PCR primers are underlined. Putative transcription factor binding sites analysed by in silico analysis (Genomatix, Matlnspector version 7.7.3.I) are indicated in red. Probes for EMSA to investigate interference of SpI and NF- $\kappa$ B binding by DNA methylation are in bold and italic. The color reproduction of the figure is available at the British Journal of Cancer journal online.

The repressive histone modifications $\mathrm{H} 3 \mathrm{~K} 9 \mathrm{me} 3$ as well as H3K27me3 were not detected in EpCAM-positive cells. Interestingly, in the EpCAM-negative cells, region A1 was associated with repressive marks: in A2780, region A1 was associated with $\mathrm{H} 3 \mathrm{~K} 9 \mathrm{me} 3$; whereas in H134S the promoter was associated with H3K27me3 (Figure 3D, Table 1).

\section{In vivo epcam gene occupancy by transcription factors}

Locations of transcription factor binding sites in the epcam promoter as described in literature (Linnenbach et al, 1993;
McLaughlin et al, 2004; Yamashita et al, 2007; Sankpal et al, 2009), as well as additional putative sites obtained by Genomatix MatInspector are shown in Figure 1B. The transcription factors screened for in vivo association with the epcam promoter were selected based on evidence for a biological role in epcam regulation (Gires et al, 2001; Tai et al, 2007; Yamashita et al, 2007; Sankpal et al, 2009) and their potential role in ovarian cancer (Anttila et al, 2000; Reimer et al, 2007; Min and Wei-hong, 2009; Oettgen, 2010).

In the EpCAM-positive OVCAR3 cells, the promoter was associated with Sp1, NF- $\kappa$ B, LEF-1, E2F2, Ets1 and Ets2 for both regions tested (Table 2 and Figure 4), whereas E2F4, p53, AP2 $\alpha$ and STAT3 were only associated with region B1. In the EpCAM- 
A

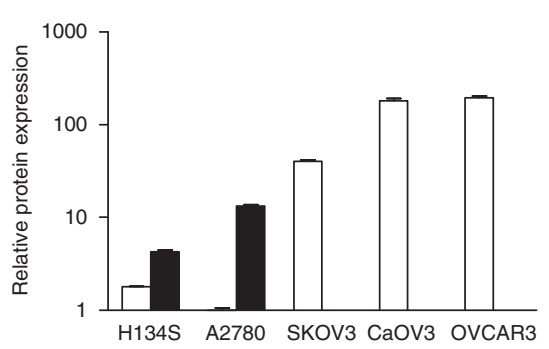

B

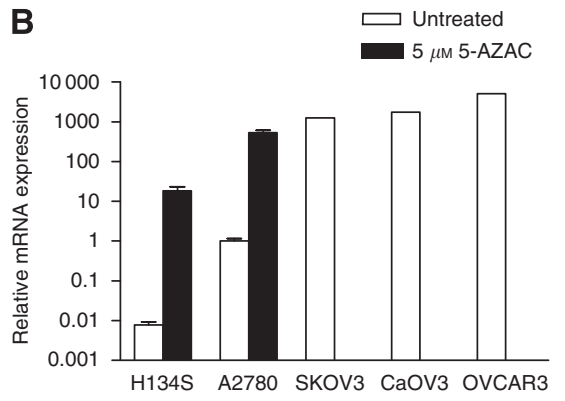

C

\begin{tabular}{|l|l|l|l|l|l|}
\hline DNA methylation & A2780 & H134S & SKOV3 & CaOV3 & OVCAR3 \\
\hline Region A & $100 \%(4)$ & $89 \%(6)$ & $1 \%(9)$ & $0.5 \%(6)$ & $0 \%(6)$ \\
\hline Region B & $99 \%(11)$ & $56 \%(10)$ & $9 \%(10)$ & $3 \%(10)$ & $1 \%(10)$ \\
\hline
\end{tabular}

Figure 2 EpCAM expression in correlation with DNA methylation in ovarian cancer. To compare EpCAM expression between the different cell lines, untreated A2780 was set at I. (A) The average ( \pm s.d.) of the relative mean fluorescence intensity of one representative staining performed in triplicate is shown. (B) Quantitative RT-PCR analysis showing relative EpCAM mRNA levels. (C) The \% of DNA methylation represents the number of methylated CpGs divided by the total number of CpGs present in the region. For each cell line the number of clones analysed is indicated between brackets.

Table I Epigenetic marks associated with EpCAM expression

\begin{tabular}{lccccc}
\hline & A2780 & HI34S & SKOV3 & CaOV3 & OVCAR3 \\
\hline EpCAM expression & - & - & + & ++ & ++ \\
& & & & & \\
Active histone marks, region C/B2 & & & & \\
acH4 & - & - & + & + & + \\
acH3 & - & - & + & + & + \\
H3K4me3 & - & - & + & + & + \\
& & & & & \\
Active histone marks, region & Al & & & & \\
acH4 & - & - & ++ & ++ & ++ \\
acH3 & - & - & ++ & ++ & ++ \\
H3K4me3 & - & - & ++ & ++ & ++ \\
& & & & & \\
Repressive histone marks, region C/B2 & & & & - \\
H3K9me3 & - & - & - & - & - \\
H3K27me3 & - & - & - & - & - \\
Repressive histone marks, region & Al & & & & - \\
H3K9me3 & + & - & - & - & - \\
H3K27me3 & - & + & - & - & - \\
DNA methylation & +++ & ++ & + - & - & - \\
Region B/A & & & & & \\
\hline
\end{tabular}

positive $\mathrm{CaOV} 3$ cells, the promoter was associated with the same transcription factors as for OVCAR3, except that for p53 and STAT3 no association was detected. The transcription factors LEF-1 and Ets1 were associated with region A1, whereas association of Sp1, E2F2, Ets2 and again AP-2 $\alpha$ were only found in region B1. In the EpCAM-negative cells A2780 and H134S, no association of any of the transcription factors with region A1 nor with region $\mathrm{B} 1$ was detected (Table 2). In addition, no association of ESE-1, SNAI1, SLUG, PEA3 and PDEF was detected neither in EpCAM-positive nor in EpCAM-negative cells (data not shown).

\section{Interference on binding of transcription factors by DNA methylation}

The ChIP data suggest a role for NF- $\kappa \mathrm{B}$ and Sp1 in regulating epcam gene expression. Our bisulphite sequencing revealed that the $\mathrm{CpG}$ next to the putative binding site of NF- $\kappa \mathrm{B}$ (located at
$+27, \mathrm{NF}-\kappa \mathrm{B}$ in Figure $1 \mathrm{~B})$ was methylated in all clones of the epcam-negative cells and not methylated in the EpCAM-positive cells. Similarly, for the $\mathrm{CpG}$ present in a putative binding site for Sp1 (located at -32, Sp1b in Figure 1B), complete methylation in all clones was observed in the EpCAM-negative cells, whereas in the EpCAM-positive cells this particular CpG was not once methylated. Also the $2 \mathrm{CpGs}$ present in two putative binding sites for Sp1 (located at -231 and $-226, S p 1 a$ in Figure 1B), were both methylated in the EpCAM-negative cells (A2780: 22/22 clones, H134S: 14/20 clones), whereas in the EpCAM-positive cells, these two CpGs were not methylated (SKOV3 and CaOV3: 1/20 clones, OVCAR3: 0/20 clones).

To investigate whether the observed DNA methylation actually interferes with binding of the transcription factors to the epcam promoter, EMSA competition studies were performed. Shift assay with unmethylated probe Spla (Figure 1B) and nuclear protein extract of OVCAR3 cells revealed two bands $(a+b)$ (Figure 5A). Both bands were also observed for the methylated Spla probe, but the binding of nuclear protein to the methylated probe was less efficient than to the unmethylated probe (lane 2 compared with 6). Also competition with an excess of cold unmethylated Spla probe was more efficient than with a methylated probe, indicating that Sp1 binds preferentially to the unmethylated Spla binding site within the epcam promoter. Shift assay with the Sp1b probe and nuclear extract of OVCAR3 cells revealed two bands with the unmethylated probe as well as with the methylated probe (Figure 5B). One of the bands is not specific (NS), as the band intensity was not reduced with an excess of competitor. The other band indicated with an $S$, showed competition with both an excess of unmethylated as well as an excess of methylated probe, indicating that for this particular sequence the transcription factor binds to the Sp1b probe, regardless of DNA methylation status of the $\mathrm{CpGs}$ within this probe. Also for the NF- $\kappa \mathrm{B}$ probe, no difference in binding patterns to the methylated and unmethylated NF- $\kappa$ B probes was observed (data not shown).

\section{DISCUSSION}

Epigenetic aberrations, including DNA methylation and histone modifications, are well established in the development and progression of ovarian cancer (Barton et al, 2008; Balch et al, 2009). A number of protein-coding genes are overexpressed in ovarian cancer because of loss of DNA methylation, including 

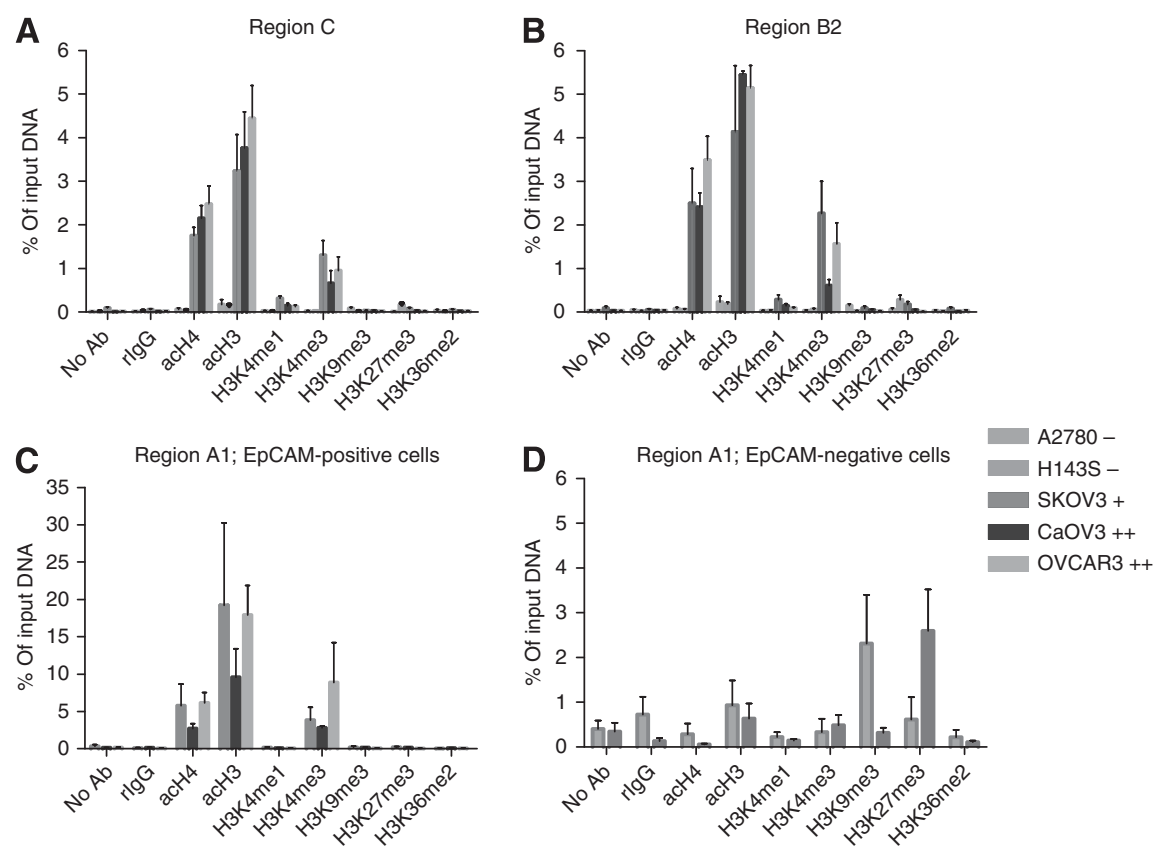

Figure 3 Histone modifications associated with EpCAM expression. Histone modifications associated with region C (A), region B2 (B) and AI (C and $\mathbf{D})$ within the epcam gene in EpCAM-negative $(-)$ and -positive $(+)$ cells. The absence of antibody (no Ab) and rlgG were used as negative controls. The bars represent the mean of three or more independent ChIP experiments \pm the s.e.m.

Table 2 Transcription factors associated with the epcam gene ( $+=$ association, $-=$ no association)

\section{SpI NF- $\kappa$ B LEF-I E2F2 E2F4 EtsI Ets2 p53 AP2 $\alpha$ STAT3}

\begin{tabular}{|c|c|c|c|c|c|c|c|c|c|c|}
\hline \multicolumn{11}{|c|}{ OVCAR3 } \\
\hline Al & + & + & + & + & - & + & + & - & - & - \\
\hline BI & + & + & + & + & + & + & + & + & + & + \\
\hline \multicolumn{11}{|c|}{ CaOV3 } \\
\hline $\mathrm{Al}$ & - & + & + & - & + & + & - & - & - & - \\
\hline $\mathrm{BI}$ & + & + & - & + & + & - & + & - & + & - \\
\hline \multicolumn{11}{|c|}{ A2780 } \\
\hline Al & - & - & - & - & - & - & - & - & - & - \\
\hline BI & - & - & - & - & - & - & - & - & - & - \\
\hline \multicolumn{11}{|c|}{ HI34S } \\
\hline $\mathrm{Al}$ & - & - & - & - & - & - & - & - & - & - \\
\hline BI & - & - & - & - & - & - & - & - & - & - \\
\hline
\end{tabular}

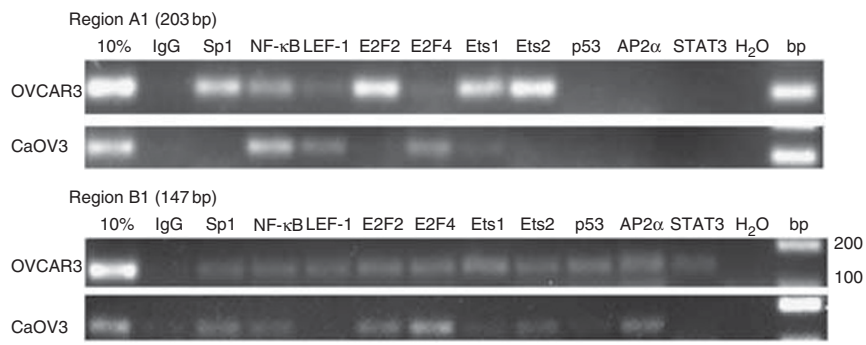

Figure 4 Transcription factors associated with the epcam gene. ChIP analysis on EpCAM-positive (OVCAR3, CaOV3) cells performed with the indicated antibodies, lgG was used as a negative control, $10 \%=10 \%$ of input; PCR was performed with primers for regions $\mathrm{AI}$ and $\mathrm{BI}$. maspin, claudin-3 (Honda et al, 2007) and claudin-4 (Barton et al, 2008). In addition, overall loss of the repressive histone mark H3K27me3 has been associated with poor prognosis in ovarian cancer (Wei et al, 2008). In this study, we set out to unravel the epigenetic marks underlying EpCAM overexpression in ovarian cancer.

In our ovarian cancer cell line panel, EpCAM expression was inversely correlated with the DNA methylation status of the promoter and part of exon 1, as reported for several other tumour types (Spizzo et al, 2007; Tai et al, 2007; Yu et al, 2008; van der Gun et al, 2008). Interestingly, treatment of our EpCAM-negative ovarian cancer cells with a DNA methylation inhibitor induced EpCAM expression, both on mRNA and protein level. The role of DNA methylation in silencing epcam has been previously published by us for the intermediate epcam expressing SKOV3 ovarian cancer cells, and is in line with observations in other tumour types (Spizzo et al, 2007; Tai et al, 2007; van der Gun et al, 2008). In normal cells (HOSE), we did not find DNA hypermethylation, even though in several ovarian cancer cell lines, including SKOV3, CaOV3 and OVCAR3, EpCAM mRNA was reported to be 3 log higher compared with HOSE cells (Kim et al, 2003). Also on protein level, HOSE cultures showed negative to negligible levels of EpCAM expression (Bellone et al, 2009). This unexpected low DNA methylation level for EpCAM in HOSE cells is in line with data of differentiating human embryonic stem cells, where epcam silencing was not associated with increased DNA methylation (Lu et al, 2010). In these cells, epcam silencing was associated with a reduction of active histone marks and an enhancement of repressive histone marks ( $\mathrm{Lu}$ et al, 2010). Also in our panel of EpCAM-negative cell lines, we found the silenced epcam promoter to be associated with repressive marks (H3K9 or H3K27 trimethylation), and relative low levels of active histone marks ( $\mathrm{H} 3 / \mathrm{H} 4$ acetylation, $\mathrm{H} 3 \mathrm{~K} 4$ trimethylation) were observed.

The epigenetic marks found in the EpCAM-negative cells indicate a closed chromatin conformation, which might explain 

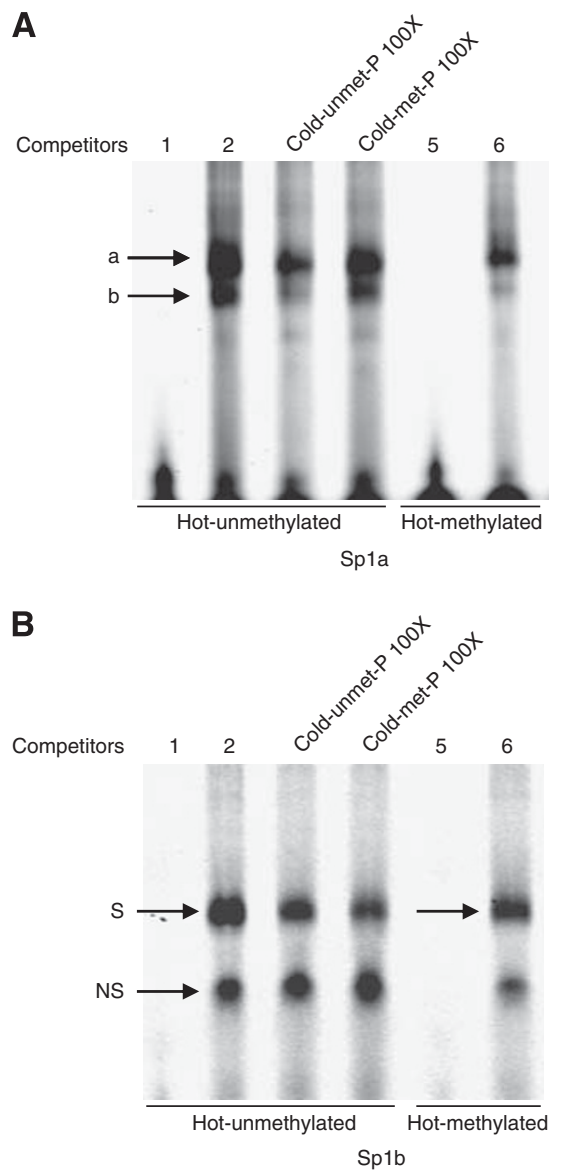

Figure 5 Interference of DNA methylation on binding of Spl. Competition EMSA's were performed with hot (un)methylated (A) Spla and (B) Splb probes and nuclear extracts (NE) of OVCAR3 cells. The specificity and methylation sensitivity of the band of interest were shown by using the cold competitors (lanes I, 5: probe; lanes 2, 6: probe with NE; lanes 3, 4: probe with NE in the presence of 100 -fold excess of indicated competitor).

the absence of association of any of the tested transcription factors with the epcam gene in $\mathrm{H} 134 \mathrm{~S}$ and $\mathrm{A} 2780$ cells. Out of the 16 tested transcription factors, 10 were associated with the promoter in the EpCAM-expressing cells. We are the first to show association of AP2 $\alpha$, Ets1, Ets2, E2F2, E2F4 and STAT3 with the epcam gene. Of special interest are the associations found for nuclear AP2 $\alpha$ and Ets1, as high levels of these transcription factors have been related to poor prognosis in ovarian cancer (Anttila et al, 2000; Oettgen, 2010). Similarly, a high E2F2 to E2F4 ratio was reported to be of prognostic value for ovarian cancer-free survival (Reimer et al, 2007). Also STAT3 is overexpressed in ovarian cancer compared with normal or benign ovarian tumour tissue, and its expression was significantly higher in FIGO stage III/IV compared with stage I/II (Min and Wei-hong, 2009). Although our data indicate that the relation between transcription factors and clinical parameters might partially take place via EpCAM expression regulation, the direct biological significance needs to be further established.

For the transcription factors, p53, NF- $\kappa \mathrm{B}, \mathrm{Sp} 1$ and LEF-1 (Yamashita et al, 2007), evidence for regulating EpCAM expression was previously demonstrated in other tumour types. Although wild-type p53, but not mutant p53, has been reported to repress EpCAM expression (Sankpal et al, 2009), we did not observe p53 association in EpCAM-negative cells. The observed association of p53 in the EpCAM-positive, p53-mutant OVCAR3 cells (Kolfschoten et al, 2002) is in agreement with the acetylated histones associated with the promoter in these cells, as mutant p53 recruits the histone acetyl transferase p300 (Strano et al, 2007). In the presence of p300, the repressive action of NF- $\kappa \mathrm{B}$ on epcam promoter activity was abolished (Gires et al, 2001), which might explain the association of NF- $\kappa \mathrm{B}$ and acetylated histones with the EpCAM promoter in EpCAM-positive cells. Also Sp1 has previously been reported to be involved in EpCAM transcription (Tai et al, 2007). Interestingly, our observation that the CpGs located around -230 within the Sp1 binding sites were methylated in EpCAM-negative ovarian cell lines and unmethylated in the EpCAM-positive lines was also reported for several other types of tumours ( $\mathrm{Yu}$ et al, 2008). Together with our in vitro finding that methylation of these particular CpGs affects Sp1 binding, this region is currently explored by us for targeted DNA methylation approaches (van der Gun et al, 2010a).

Apart from DNA methylation and histone modifications, other epigenetic mechanisms, including non-coding RNAs, may be (directly and indirectly) involved in epcam gene regulation. In this respect, microRNA-181 has been shown to upregulate epcam gene expression, possibly via a positive feedback loop between miR-181 and $\mathrm{Wnt} / \beta$-catenin signalling (Ji et al, 2011). These observations are in line with our data showing association of the Wnt-pathway transcription factor LEF-1 with the active epcam promoter. Alternatively, several endogenous non-coding RNAs have been reported to be capable of modulating gene expression directly on the transcriptional level, for example, by inducing DNA methylation (Morris, 2011).

At present, EpCAM is exploited as therapeutic target in several antibody-based clinical trials. Recently, the European Medicines Agency approved the use of catumaxomab for the intraperitoneal treatment of malignant ascites (Bokemeyer, 2010). The oncogenic role of EpCAM broadens the interest to use EpCAM not only as an immunotarget but also as a target for epigenetic silencing. In this respect, transient siRNA-mediated silencing of EpCAM expression has been shown to reduce the oncogenic potential of breast (Osta et al, 2004), gastric (Du et al, 2009), hepatocellular (Yamashita et al, 2009) and oral squamous cell (Yanamoto et al, 2007) carcinomas.

To silence gene expression in a more sustained way, targeted DNA methylation has been achieved by fusing a DNA methyltransferase to a DNA binding domain like zinc-fingers (Smith et al, 2008). Similarly, transcription effector domains fused to zincfingers targeting the epcam promoter modulated epcam promoter activity (Gommans et al, 2007). Recently, we showed that an EpCAM-specific triple helix-forming oligonucleotide coupled to a methyltransferase variant is able to target methylation predominantly to a specific CpG in the epcam promoter (van der Gun et al, 2010a). Interestingly, targeted methylation in living cells induced dense methylation up to $380 \mathrm{bp}$ on both sides of the target site (Li et al, 2007), suggesting that initial DNA methylation might serve as a trigger for DNA methylation spreading. Elucidating the regulation mechanisms of epcam in ovarian cancer as presented here thus opens up new possibilities to exploit EpCAM as a therapeutic target.

\section{ACKNOWLEDGEMENTS}

This study has been partially funded by the EU FP7 EuroTransBio: ProTuMa ET09008. We thank JM Dokter-Fokkens (UMCG) for culturing the cell lines.

Supplementary Information accompanies the paper on British Journal of Cancer website (http://www.nature.com/bjc) 


\section{REFERENCES}

Anttila MA, Kellokoski JK, Moisio KI, Mitchell PJ, Saarikoski S, Syrjanen K, Kosma VM (2000) Expression of transcription factor AP-2alpha predicts survival in epithelial ovarian cancer. Br J Cancer 82: 1974-1983

Balch C, Fang F, Matei DE, Huang TH, Nephew KP (2009) Mini review: epigenetic changes in ovarian cancer. Endocrinology 150: 4003-4011

Barton CA, Hacker NF, Clark SJ, O'Brien PM (2008) DNA methylation changes in ovarian cancer: implications for early diagnosis, prognosis and treatment. Gynecol Oncol 109: 129-139

Bellone S, Siegel ER, Cocco E, Cargnelutti M, Silasi DA, Azodi M, Schwartz PE, Rutherford TJ, Pecorelli S, Santin AD (2009) Overexpression of epithelial cell adhesion molecule in primary, metastatic, and recurrent/chemotherapy-resistant epithelial ovarian cancer: implications for epithelial cell adhesion molecule-specific immunotherapy. Int $J$ Gynecol Cancer 19: $860-866$

Bokemeyer C (2010) Catumaxomab - trifunctional anti-EpCAM antibody used to treat malignant ascites. Expert Opin Biol Ther 10: 1259-1269

Du W, Ji H, Cao S, Wang L, Bai F, Liu J, Fan D (2009) EpCAM: a potential antimetastatic target for gastric cancer. Dig Dis Sci 55: 1033-1038

Gires O, Kieu C, Fix P, Schmitt B, Munz M, Wollenberg B, Zeidler R (2001) Tumor necrosis factor alpha negatively regulates the expression of the carcinoma-associated antigen epithelial cell adhesion molecule. Cancer 92: $620-628$

Gommans WM, McLaughlin PM, Lindhout BI, Segal DJ, Wiegman DJ, Haisma HJ, van der Zaal BJ, Rots MG (2007) Engineering zinc finger protein transcription factors to downregulate the epithelial glycoprotein-2 promoter as a novel anti-cancer treatment. Mol Carcinog 46: $391-401$

Heinzelmann-Schwarz VA, Gardiner-Garden M, Henshall SM, Scurry J, Scolyer RA, Davies MJ, Heinzelmann M, Kalish LH, Bali A, Kench JG, Edwards LS, Bergh PMV, Hacker NF, Sutherland RL, O'Brien PM (2004) Overexpression of the cell adhesion molecules DDR1, claudin 3, and Ep-CAM in metaplastic ovarian epithelium and ovarian cancer. Clin Cancer Res 10: $4427-4436$

Honda H, Pazin MJ, D'Souza T, Ji H, Morin PJ (2007) Regulation of the CLDN3 gene in ovarian cancer cells. Cancer Biol Ther 6: 1733-1742

Ji J, Yamashita T, Wang XW (2011) Wnt/beta-catenin signaling activates microRNA-181 expression in hepatocellular carcinoma. Cell Bioscience 1: $1-8$

Kim JH, Herlyn D, Wong KK, Park DC, Schorge JO, Lu KH, Skates SJ, Cramer DW, Berkowitz RS, Mok SC (2003) Identification of epithelial cell adhesion molecule autoantibody in patients with ovarian cancer. Clin Cancer Res 9: 4782-4791

Klatte T, Pantuck AJ, Said JW, Seligson DB, Rao NP, LaRochelle JC, Shuch B, Zisman A, Kabbinavar FF, Belldegrun AS (2009) Cytogenetic and molecular tumor profiling for Type 1 and Type 2 papillary renal cell carcinoma. Clin Cancer Res 15: $1162-1169$

Kobel M, Kalloger SE, Boyd N, McKinney S, Mehl E, Palmer C, Leung S, Bowen NJ, Ionescu DN, Rajput A, Prentice LM, Miller D, Santos J, Swenerton K, Gilks CB, Huntsman D (2008) Ovarian carcinoma subtypes are different diseases: implications for biomarker studies. PLoS Med 5: e232

Kolfschoten GM, Hulscher TM, Schrier SM, van Houten VMM, Pinedo HM, Boven E (2002) Time-dependent changes in factors involved in the apoptotic process in human ovarian cancer cells as a response to cisplatin. Gynecol Oncol 84: 404-412

Li F, Papworth M, Minczuk M, Rohde C, Zhang Y, Ragozin S, Jeltsch A (2007) Chimeric DNA methyltransferases target DNA methylation to specific DNA sequences and repress expression of target genes. Nucleic Acids Res 35: $100-112$

Linnenbach AJ, Seng BA, Wu S, Robbins S, Scollon M, Pyrc JJ, Druck T, Huebner K (1993) Retroposition in a family of carcinoma-associated antigen genes. Mol Cell Biol 13: 1507-1515

Lu TY, Lu RM, Liao MY, Yu J, Chung CH, Kao CF, Wu HC (2010) Epithelial cell adhesion molecule regulation is associated with the maintenance of the undifferentiated phenotype of human embryonic stem cells. J Biol Chem 285: 8719-8732

Maetzel D, Denzel S, Mack B, Canis M, Went P, Benk M, Kieu C, Papior P, Baeuerle PA, Munz M, Gires O (2009) Nuclear signalling by tumourassociated antigen EpCAM. Nat Cell Biol 11: 162-171

McLaughlin PM, Trzpis M, Kroesen BJ, Helfrich W, Terpstra P, Dokter WH, Ruiters MH, de Leij LF, Harmsen MC (2004) Use of the EGP-2/Ep-CAM promoter for targeted expression of heterologous genes in carcinoma derived cell lines. Cancer Gene Ther 11: 603-612
Min H, Wei-hong Z (2009) Constitutive activation of signal transducer and activator of transcription 3 in epithelial ovarian carcinoma. J Obstet Gynaecol Res 35: 918-925

Morris KV (2011) Modulation of gene-specific epigenetic states and transcription by non-coding RNAs. Clin Epigenet; e-pub ahead of print 28 April 2011; DOI: 10.1007/s13148-011-0034-6

Oettgen P (2010) The role of ets factors in tumor angiogenesis. J Oncol 2010: 767384

Osta WA, Chen Y, Mikhitarian K, Mitas M, Salem M, Hannun YA, Cole DJ, Gillanders WE (2004) EpCAM is overexpressed in breast cancer and is a potential target for breast cancer gene therapy. Cancer Res 64: $5818-5824$

Reimer D, Sadr S, Wiedemair A, Stadlmann S, Concin N, Hofstetter G, Muller-Holzner E, Marth C, Zeimet AG (2007) Clinical relevance of E2F family members in ovarian cancer - an evaluation in a training set of 77 patients. Clin Cancer Res 13: $144-151$

Sankpal NV, Willman MW, Fleming TP, Mayfield JD, Gillanders WE (2009) Transcriptional repression of epithelial cell adhesion molecule contributes to p53 control of breast cancer invasion. Cancer Res 69: $753-757$

Seligson DB, Pantuck AJ, Liu X, Huang Y, Horvath S, Bui MH, Han KR, Correa AJ, Eeva M, Tze S, Belldegrun AS, Figlin RA (2004) Epithelial cell adhesion molecule (KSA) expression: pathobiology and its role as an independent predictor of survival in renal cell carcinoma. Clin Cancer Res 10: 2659-2669

Smith AE, Hurd PJ, Bannister AJ, Kouzarides T, Ford KG (2008) Heritable gene repression through the action of a directed DNA methyltransferase at a chromosomal locus. J Biol Chem 283: 9878-9885

Spizzo G, Fong D, Wurm M, Ensinger C, Obrist P, Hofer C, Mazzoleni G, Gastl G, Went P (2011) EpCAM expression in primary tumour tissues and metastases: an immunohistochemical analysis. J Clin Pathol 64: $415-420$

Spizzo G, Gastl G, Obrist P, Fong D, Haun M, Grunewald K, Parson W, Eichmann C, Millinger S, Fiegl H, Margreiter R, Amberger A (2007) Methylation status of the Ep-CAM promoter region in human breast cancer cell lines and breast cancer tissue. Cancer Lett 246: 253-261

Spizzo G, Went P, Dirnhofer S, Obrist P, Moch H, Baeuerle PA, MuellerHolzner E, Marth C, Gastl G, Zeimet AG (2006) Overexpression of epithelial cell adhesion molecule (Ep-CAM) is an independent prognostic marker for reduced survival of patients with epithelial ovarian cancer. Gynecol Oncol 103: 483-488

Spizzo G, Went P, Dirnhofer S, Obrist P, Simon R, Spichtin H, Maurer R, Metzger U, von CB, Bart R, Stopatschinskaya S, Kochli OR, Haas P, Mross F, Zuber M, Dietrich H, Bischoff S, Mirlacher M, Sauter G, Gastl G (2004) High Ep-CAM expression is associated with poor prognosis in node-positive breast cancer. Breast Cancer Res Treat 86: 207-213

Strano S, Dell'orso S, Di AS, Fontemaggi G, Sacchi A, Blandino G (2007) Mutant p53: an oncogenic transcription factor. Oncogene 26: 2212-2219

Tai KY, Shiah SG, Shieh YS, Kao YR, Chi CY, Huang E, Lee HS, Chang LC, Yang PC, Wu CW (2007) DNA methylation and histone modification regulate silencing of epithelial cell adhesion molecule for tumor invasion and progression. Oncogene 26: 3989-3997

van der Gun BT, Maluszynska-Hoffman M, Kiss A, Arendzen AJ, Ruiters MH, McLaughlin PM, Weinhold E, Rots MG (2010a) Targeted DNA methylation by a DNA methyltransferase coupled to a triple helix forming oligonucleotide to down-regulate the epithelial cell adhesion molecule. Bioconjug Chem 21: 1239-1245

van der Gun BT, Wasserkort R, Monami A, Jeltsch A, Rasko T, Slaska-Kiss K, Cortese R, Rots MG, de Leij LF, Ruiters MH, Kiss A, Weinhold E, McLaughlin PM (2008) Persistent downregulation of the pancarcinoma-associated epithelial cell adhesion molecule via active intranuclear methylation. Int J Cancer 123: 484-489

van der Gun BTF, Melchers LJ, Ruiters MHJ, de Leij LFMH, McLaughlin PMJ, Rots MG (2010b) EpCAM in carcinogenesis: the good, the bad or the ugly. Carcinogenesis 31: 1913-1921

Visvader JE, Lindeman GJ (2008) Cancer stem cells in solid tumours: accumulating evidence and unresolved questions. Nat Rev Cancer 8: $755-768$

Wei Y, Xia W, Zhang Z, Liu J, Wang H, Adsay NV, Albarracin C, Yu D, Abbruzzese JL, Mills GB, Bast Jr RC, Hortobagyi GN, Hung MC (2008) Loss of trimethylation at lysine 27 of histone $\mathrm{H} 3$ is a predictor of poor outcome in breast, ovarian, and pancreatic cancers. Mol Carcinog 47: $701-706$ 
Weinmann AS, Farnham PJ (2002) Identification of unknown target genes of human transcription factors using chromatin immunoprecipitation. Methods 26: $37-47$

Wimberger P, Heubner M, Lindhofer H, Jager M, Kimmig R, Kasimir-Bauer S (2009) Influence of catumaxomab on tumor cells in bone marrow and blood in ovarian cancer. Anticancer Res 29: 1787-1791

Xiang W, Wimberger P, Dreier T, Diebold J, Mayr D, Baeuerle PA, Kimmig R (2003) Cytotoxic activity of novel human monoclonal antibody MT201 against primary ovarian tumor cells. J Cancer Res Clin Oncol 129: 341 - 348

Yamashita T, Budhu A, Forgues M, Wang XW (2007) Activation of hepatic stem cell marker EpCAM by Wnt \{beta\}-catenin signaling in hepatocellular. Cancer Res 67: $10831-10839$
Yamashita T, Ji J, Budhu A, Forgues M, Yang W, Wang HY, Jia H, Ye Q, Qin LX, Wauthier E, Reid LM, Minato H, Honda M, Kaneko S, Tang ZY, Wang XW (2009) EpCAM-positive hepatocellular carcinoma cells are tumor-initiating cells with stem/progenitor cell features. Gastroenterology 136: 1012 - 1024

Yanamoto S, Kawasaki G, Yoshitomi I, Iwamoto T, Hirata K, Mizuno A (2007) Clinicopathologic significance of EpCAM expression in squamous cell carcinoma of the tongue and its possibility as a potential target for tongue cancer gene therapy. Oral Oncol 43: $869-877$

Yu G, Zhang X, Wang H, Rui D, Yin A, Qiu G, He Y (2008) CpG island methylation status in the EpCAM promoter region and gene expression. Oncol Rep 20: $1061-1067$ 